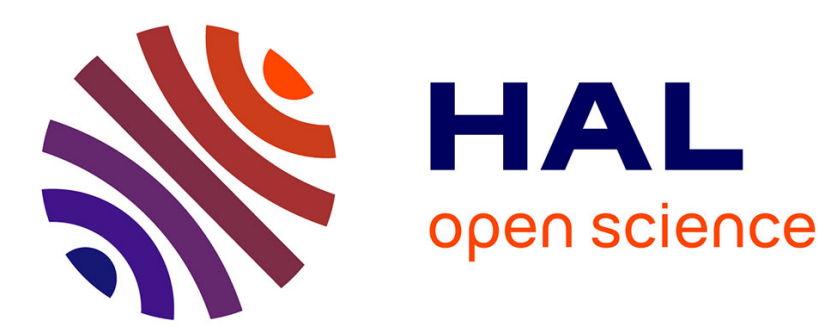

\title{
The Motion of an Azobenzene Light-Controlled Switch: A Joint Theoretical and Experimental Approach
}

Bérangère Godde, Abdelaziz Jouaiti, Matteo Mauro, Roberto Marquardt, Alain Chaumont, Vincent Robert

\section{- To cite this version:}

Bérangère Godde, Abdelaziz Jouaiti, Matteo Mauro, Roberto Marquardt, Alain Chaumont, et al.. The Motion of an Azobenzene Light-Controlled Switch: A Joint Theoretical and Experimental Approach. ChemSystemsChem, 2019, 1 (3), pp.e1900003. 10.1002/syst.201900003 . hal-03011738

\author{
HAL Id: hal-03011738 \\ https://hal.science/hal-03011738
}

Submitted on 18 Nov 2020

HAL is a multi-disciplinary open access archive for the deposit and dissemination of scientific research documents, whether they are published or not. The documents may come from teaching and research institutions in France or abroad, or from public or private research centers.
L'archive ouverte pluridisciplinaire HAL, est destinée au dépôt et à la diffusion de documents scientifiques de niveau recherche, publiés ou non, émanant des établissements d'enseignement et de recherche français ou étrangers, des laboratoires publics ou privés. 


\title{
The Motion of an Azobenzene Light-Controlled Switch: A Joint Theoretical and Experimental Approach
}

\author{
Bérangère Godde, ${ }^{*[a]}$ Abdelaziz Jouaiti, ${ }^{[a]}$ Matteo Mauro, ${ }^{* b]}$ Roberto Marquardt, ${ }^{[c]}$ Alain \\ Chaumont, ${ }^{*[d]}$ and Vincent Robert ${ }^{[c]}$. \\ [a] Laboratoire de Tectonique Moléculaire UMR UDS-CNRS 7140, icFRC Université de Strasbourg Institut Le Bel, 4, rue B. \\ Pascal, F-67000, Strasbourg (France). \\ [b] Institut de Physique et Chimie des Matériaux de Strasbourg UMR UDS-CNRS 7504, Université de Strasbourg 23, rue du \\ Loess, F-67000 Strasbourg (France) \\ [c] Laboratoire de Chimie Quantique Institut de Chimie, UMR UDS-CNRS 7177 Université de Strasbourg Institut Le Bel, 4, rue \\ B. Pascal, F-67000 Strasbourg (France) \\ [d] Laboratoire de Chimie Moléculaire de l'Etat Solide UMR UDS-CNRS 7140, Université de Strasbourg Institut Le Bel, 4, rue \\ B. Pascal, F-67000 Strasbourg (France)
}

\begin{abstract}
To gain further insight into the internal motion of molecular objects, we have synthesized a molecular turnstile AzoT composed of a rotor based on flexible tetraethyleneglycol (TEG) chains grafted on aromatic moieties and a stator containing a photoswitchable azobenzene (Azo) fragment. The control of the reversible light-induced E-AzoT.Z-AzoT isomerization is supported by both NMR spectroscopy and photophysical investigation, which show that the system exhibits a fatigueless isomerization switching process. Furthermore, $2 D$ NMR spectroscopy points to the fact that the free internal motion is triggered by the E-AzoT.Z-AzoT isomerization. Using molecular dynamics simulations and DFT calculations we have investigated the nature of the internal motions. An internal rotation characterized by an energy barrier of $23 \mathrm{~kJ} / \mathrm{mol}$ is found for the Z-AzoT isomer. In contrast, this barrier reaches 151 $\mathrm{kJ} / \mathrm{mol}$ for the E-AzoT isomer, excluding any "classical" rotation at room temperature. This rotational movement could in principle occur via tunneling. A simple model calculation, however, excludes tunnelling to take place before $20 \mathrm{~ms}$.
\end{abstract}

Keywords: density functional calculations · diazo compounds molecular dynamics · molecular machines - photoswitches

The ability to make use of energy sources, either electric, chemical or radiative, to generate motion is at the fundamentalessence of biological machines and life. [1-3] Even though molecular and biochemical systems that satisfy the conditions to establish controlled and directional movements have been synthesized, [4-6] the preparation and characterization of systems that collectively operate as molecular machines remains a challenging quest. One prerequisite is to build up architectures that exhibit multi-stability characterized by distinguishable molecular structures - local minima in the potential energy surface (PES) of the electronic ground state, referred to as stations. Stations are ideally populated at will by means of external inputs. Thus, both the relative energies, i.e. thethermodynamics, and the energy barriers that separate the stations, i.e. the kinetics, must be taken into account for the design of molecular machines. In addition, one would set up the conditions to drag the system away from its thermodynamic equilibrium. Even more refined attempts would monitor the molecular dynamics and the time-dependent molecular structure via the coherent control of amplitudes and phases of the quantum mechanical state describing this structure. [7-9] One example of this is the laser induced inhibition [10-11] or enhancement [11-12] of tunnelling. 
Following the pioneering works of various groups, [13-18] light-activated molecular machines are the object of extensive investigation. [19-21] The use of light input introduces several advantages as it can be remotely applied with high spatiotemporal and energetic resolutions and a variable intensity of the perturbation. Photochemical reactions provide a straightforward approach for displacing a chemical system out of its thermodynamic equilibrium.

Prompted by the recent demonstration of unidirectional transit arising from the E.Z isomerization, [22] we wish to status on the accepted picture of rotating pieces as well as to explore whether light can be used to control the kinetics of such intramolecular motion. Tamaoki and co-workers produced a wealth of systems based on azobenzenophanes where the photosensitive Azo fragment is introduced in the more flexible macrocycle. [23-24] A light-controlled molecular brake was reported, supporting a possible suppression of internal rotation. Still, we felt that theoretical inspection might be desirable to support the mechanistic views and to rationalize the actual molecular rotation. In the meantime, Hosseini and co-workers reported on molecular turnstiles, constructed on a rotor (typically a tetraethylene glycol (TEG) chain grafted onto a porphyrin, [25-27] an organometallic [28] or an aromatic [29-30] moiety) and a stator. With the possibility to introduce a photo-sensitive group almost at will on the stator, we designed a system where the macrocycle structure would be maintained upon irradiation. Not only does it offer another system to test the concept of motion slowdown but the inherent flexibility of the turnstile would be maintained identical in both isomers. Thus, the microscopic inspection would not suffer from deep structural changes whereas the discriminating factor should be attributed

to the stator modification. We believe that such an engineering that maintains the structure of the macrocyclic loop might produce a molecular slowdown that complements previous molecular brakes. How much a simplistic steric view can be adapted to properly describe modifications in the kinetics of the geared internal rotation is at the heart of the present study.

We herein report on a synthetic strategy combining a macrocycle with a stator in which an Azo moiety can be converted from its E (E- AzOT) to Z (Z-AzoT) form by light as a wireless trigger between stations that possess different steric demand. As a proof of principle, the length of the TEG chains has been selected in such a way that the resulting system can be reversibly switched between an ideally blocked (hindered "classical" rotation) and an unlocked (allowed rotation) station. The potential of the E- and Z-AzoT isomers to yield the targeted light-controlled kinetics is jointly supported by experimental and theoretical investigations. The key element is the identification of the structural deformation and the heights of the energy barriers that must be overcome to travel along the PES. Our inspections not only offer a microscopic description of the pathway for the process, but also afford structural and energetic evidence, questioning the traditional views on free rotation. The design of future molecular machineries based on the rotation of two portions of the molecule relative to each other should benefit from the combined experimental and theoretical investigation.

The detailed procedure employed for the synthesis of AzoT is described in Scheme S1 of the Supporting Information (SI). Two multistep strategies were used, affording global yields typically larger than $38 \%$, which differ in the order of functionalization of the stator.

The design of the AzoT macrocycle (Scheme 1) stems from the molecular turnstiles previously reported, [25-30] to which a pyridyl moiety was introduced to better follow its dynamical behavior by $1 \mathrm{H}$ NMR spectroscopy. On the other side the light responsive Azo moiety can be isomerized between 
E (thermodynamically stable) and Z (metastable) using different excitation wavelengths, [22,31-32] with concomitant large geometrical change of the compound.

The dynamical behavior of the AzoT macrocycle was then investigated by both $1 \mathrm{D}$ and $2 \mathrm{D} 1 \mathrm{H}$ NMR spectroscopies and the experimental findings are supported by theoretical investigations (vide infra). The AzoT appears to be a mixture of E- and Z-isomers, the former being the major component from the $1 \mathrm{H}$ NMR spectrum. This finding is most likely due to photo-isomerization occurring under ambient light. The $1 \mathrm{H}$ NMR spectrum is displayed in Figure S1, where attributions of the $1 \mathrm{H}$ resonances were made on the basis of similar Azo derivatives. [29-30] Expectantly, full conversion of the $E / Z$ - mixture into the thermodynamically stable $E$ isomer can be attained by thermal treatment of a $\mathrm{CD}_{3} \mathrm{CN}$ solution (Figure $\mathrm{S2}$ ), a procedure that was systematically followed for all samples. The $2 \mathrm{D} 1 \mathrm{H}-$ $1 \mathrm{H}$ NOESY NMR spectrum of E-AzoT in $\mathrm{CD}_{3} \mathrm{CN}$ at $298 \mathrm{~K}$ is displayed in Figure 1 (for atom labeling see Scheme S2). Correlations between the rotor and stator protons are restricted to $\mathrm{Hs}, \mathrm{Ht}$ (pyridine moiety), $\mathrm{Hk}$ (Azo) and the protons of the TEG chains Hu (Hu'), $\mathrm{Hv}\left(\mathrm{Hv}^{\prime}\right)$. In combination with the absence of correlations between $\mathrm{HI}, \mathrm{Hq}, \mathrm{Hp}$, Ho and the protons of the TEG chains, one may first conclude that the Azo moiety lies outside the loop. Besides, the phenyl ring of the Azo is distant from to the macrocycle chains. Hence the E-AzoT isomer may not be adapted to accomplish the desired internal rotation, a feature which shall be confirmed by molecular simulations.
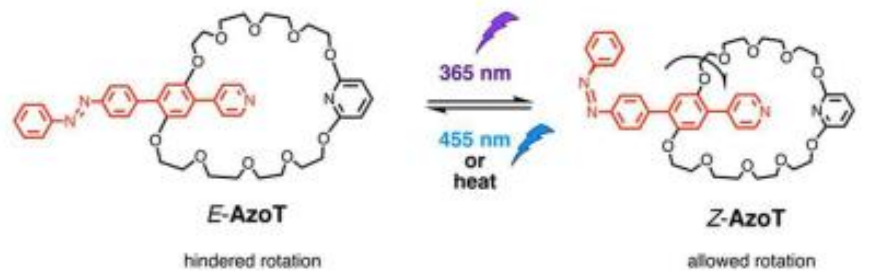

Scheme 1. Chemical structures of the AzoT macrocycle in its E- and Z-forms. Red and black portions of the molecule represent the stator and the rotor, respectively.

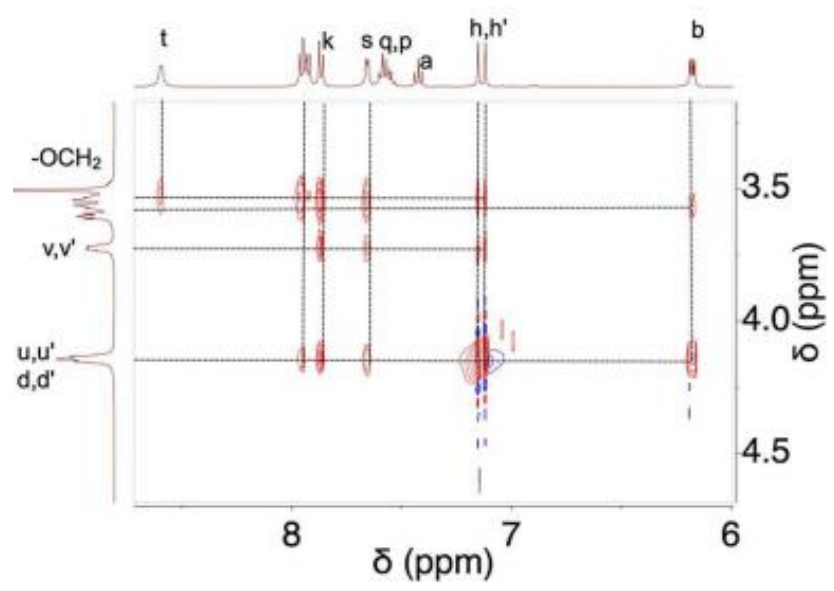

Figure 1. Aromatic region of the $1 \mathrm{H}-1 \mathrm{H}$ NMR NOESY spectrum of E-AzoT recorded in CD3CN at $298 \mathrm{~K}$.

To investigate the optical and photo-switching properties, electronic absorption spectra were recorded at a concentration of $1.0 \times 10^{-5} \mathrm{M}$ in $\mathrm{CH}_{3} \mathrm{CN}$ and $298 \mathrm{~K}$ (Figure 2a). The UV-visible absorption 
spectra of E-AzoT feature three absorption bands. The narrow and intense $\left(\varepsilon=2.0 \times 10^{4} \mathrm{M}^{-1} \mathrm{~cm}^{-1}\right)$ band centred at $\lambda$ abs $=283 \mathrm{~nm}$ can be ascribed to a $\pi-\pi^{*}$ transition. The $\lambda$ abs $=352 \mathrm{~nm}$ band $(\varepsilon=2.37 \times 10$ $\left.4 \mathrm{M}^{-1} \mathrm{~cm}^{-1}\right)$ can be ascribed to a $\pi-\pi^{*}$ transition on the Azo moiety. The much less intense $\left(\varepsilon \approx 200 \mathrm{M}^{-}\right.$ ${ }^{1} \mathrm{~cm}^{-1}$ ) absorption band at $\lambda$ abs ca. $450 \mathrm{~nm}$ corresponds to the formally symmetry-forbidden $\mathrm{n} ! \mathrm{p}^{*}$ transition on the Azo fragment.[22,33]

Continuous irradiation of E-AzoT at $\lambda$ exc $=365 \mathrm{~nm}$ induces a time-dependent change of the electron absorption features with a decrease of the $\pi-\pi^{*}$ band ( $\lambda$ abs $=352 \mathrm{~nm}$ ) and an increase of the lowest-energy lying $n-\pi^{*}$ band $(\lambda$ abs $=450 \mathrm{~nm}$ ). This indicates the light-promoted E-AzoT:Z-AzoT isomerization until the photostationary state (PSS 365 ) is finally reached (Figure 2a). To determine the PSS 365 composition, a concentrated sample of E-AzoT (1.0×10 $3 \mathrm{M})$ in CD $3 \mathrm{CN}$ was irradiated at 365 $\mathrm{nm}$ to reach PSS 365 . Signal integration of the $1 \mathrm{H}$ NMR spectrum points to a 36:64 E-AzoT:Z-AzoT ratio (Figure S3). Subsequent irradiation of the initial sample at $\lambda$ exc $=455 \mathrm{~nm}$ yields back the UV-vis spectrum, with a partial recovery of the intensity of the $\pi-\pi^{*}$ and a decrease of the $n-\pi^{*}$ band (Figure 2b). The resulting PSS 455 is characterized by a 73:27 ratio (Figure S4-S5). As previously reported, [22] the switching between PSS 365 and PSS 455 can then be repeated with almost no fatigue (Figure 2c), a prerequisite to fabricate a light-controlled rotation system.
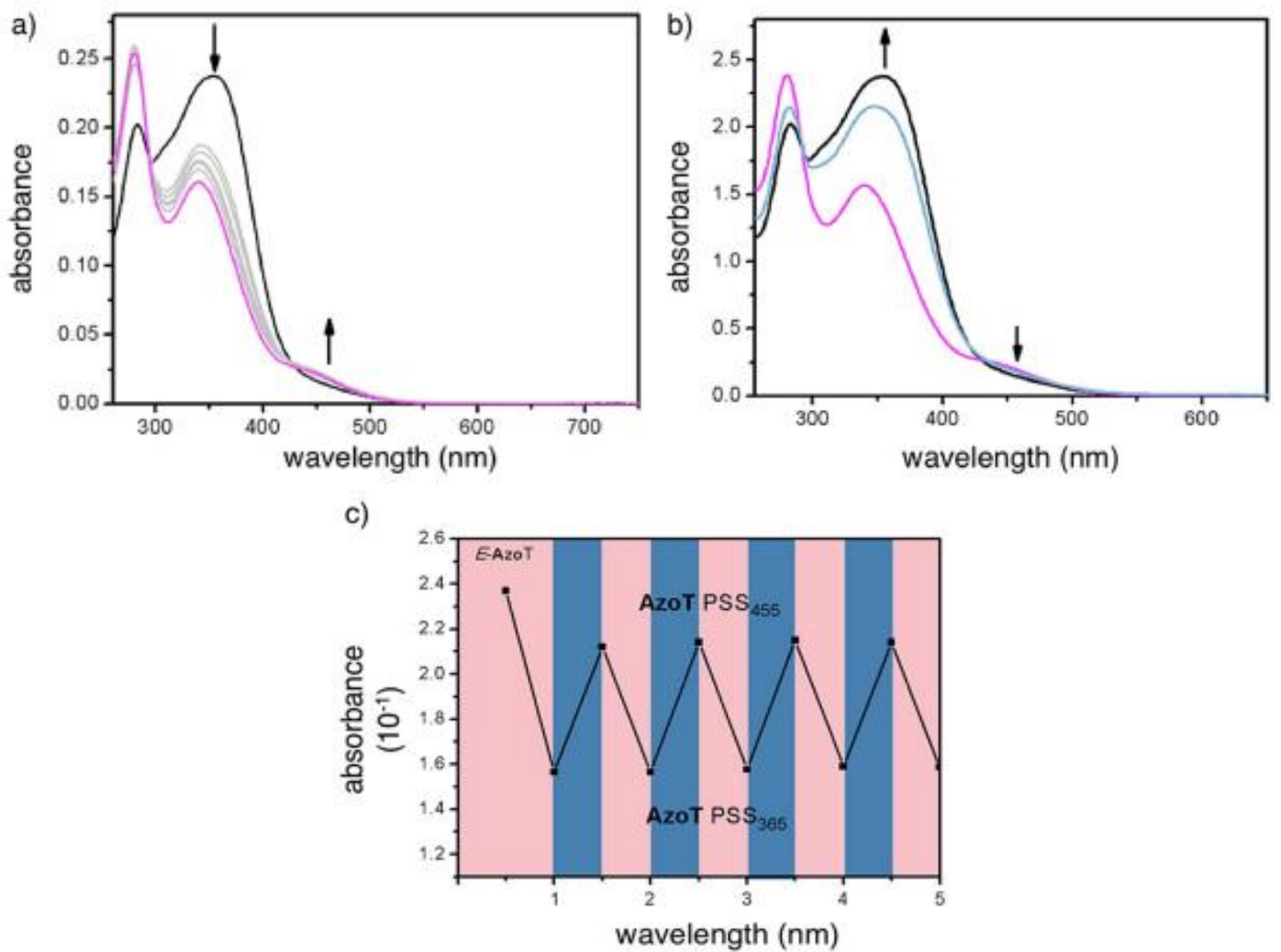

Figure 2. a) UV/Vis absorption spectra of E-AzoT at $1.0 \times 10^{-5} \mathrm{M}$ in $\mathrm{CH}_{3} \mathrm{CN}$ before (black trace) and after (violet trace) $30 \mathrm{~s}$ UV light irradiation $(\lambda$ exc $=365 \mathrm{~nm}$ ) at $298 \mathrm{~K}$ defining the photostationary state PSS 365 . Grey traces indicate intermediate irradiation times. Black arrows indicate the variation of absorbance over irradiation time; b) UV/Vis absorption spectra of AzoT at 1.0×10 $5 \mathrm{M}$ in $\mathrm{CH}_{3} \mathrm{CN}$ at the PSS 365 before (violet trace) and after (blue trace) visible light irradiation ( $\lambda$ exc $=455 \mathrm{~nm}$ ) until PSS 455 is reached. For the sake of comparison, the E-AzoT species is also displayed (black trace). c) Variation of the absorption at $\lambda$ abs $=340 \mathrm{~nm}$ upon different cycles of UV $(\lambda$ exc=365 nm) and visible $(\lambda$ exc $=455 \mathrm{~nm})$ light irradiation showing the reversibility of the photoswitching process. 
At this stage, one may question whether the timeframe needed to carry out NMR experiments is suitable for investigating a sample rich in Z-AzoT species as well, since Azo photoswitches are known to undergo thermal Z!E isomerization. Thus, this process was studied by means of spectrophotometry in $\mathrm{CH}_{3} \mathrm{CN}$ at $298 \mathrm{~K}$. After irradiation to reach PSS 455 , a sample of AzoT in $\mathrm{CH}_{3} \mathrm{CN}$ was left in the dark and thermal back isomerization investigated by means of UV-vis spectrophotometry (Figure S6a). Treatment of the time-dependent absorbance at $\lambda$ abs=340 nm (Equation S1 in SI) allowed us to estimate the back-isomerization kinetic rate constant to be $2.0 \times 10^{-6} \mathrm{~s}^{-1}$ (Figure S6b). As a conclusion, the long-lived (half-life $=96$ hours) $Z$ isomer is compatible with the NMR recording time scale. The resulting E-AzoT:Z-AzoT mixture in PSS ${ }_{365}$ was then studied by $1 \mathrm{H}-1 \mathrm{H}$ NOESY NMR spectroscopy. Given the sizeable chemical shift differences in the aromatic region between the $E$ and $Z$ isomers, two different sets of correlations can be easily evidenced in the 2D NMR spectrum (Figure 3). First, correlations can be attributed to the presence of the $\mathrm{E}$ isomer, by

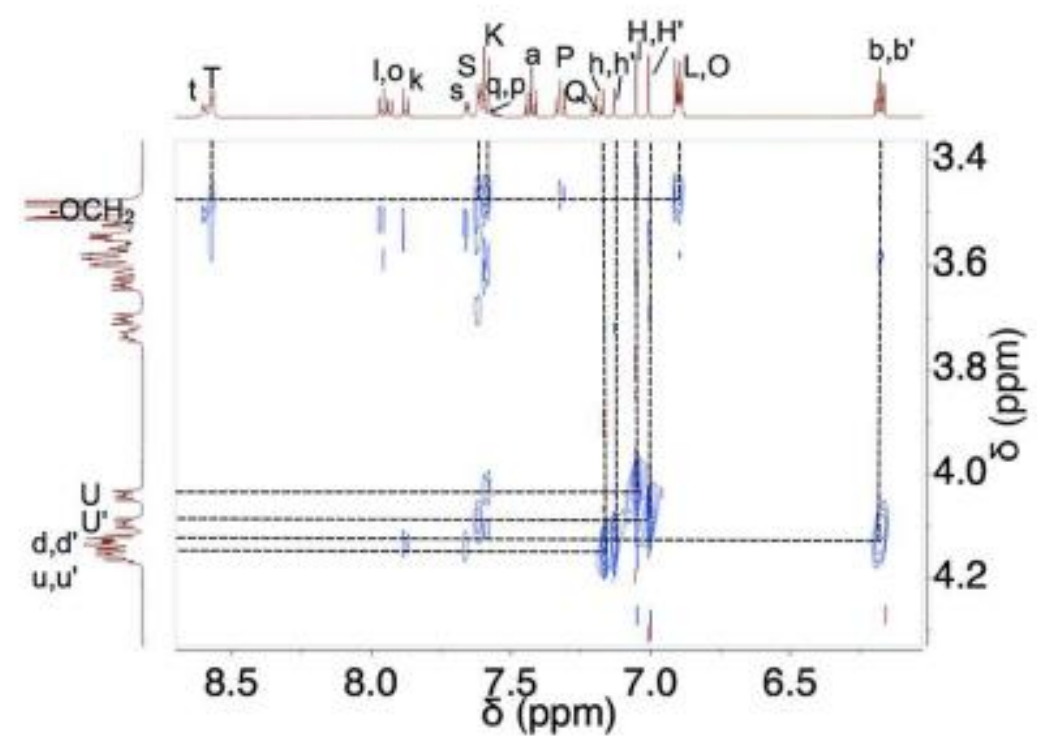

Figure 3. 2D ${ }^{1} \mathrm{H}-{ }^{1} \mathrm{H}$ NOESY NMR spectrum of AzoT at the PSS 365 recorded in $\mathrm{CD}_{3} \mathrm{CN}$ at $298 \mathrm{~K}$.

comparison with Figure 1. Then, the predominance of Z-AzoT over the thermodynamically most stable $\mathrm{E}$ isomer is apparent on the spectrum. As compared to E-AzoT, a new set of cross correlation peaks between $\mathrm{H}_{\mathrm{O}}, \mathrm{H}_{\mathrm{P}}$ and protons of the TEG chains appear for Z-AzoT. This finding indicates that the phenyl ring of the Azo lies in close proximity to the macrocycle chains. Such an observation supports the hypothesis that the Z-AzoT isomer is able to perform a rotational movement through the macrocycle. To further strengthen this picture, extensive computational investigations were carried out.

The large flexibility of the TEG chains makes them particularly interesting from a synthetic point of view, but any theoretical examination calls for particular care. Thus, such architectures were examined using both classical molecular dynamics (CMD) and density functional theory (DFT) calculations to analyse the mechanical picture (see SI for technical details). First, $20 \mu \mathrm{s} \mathrm{cMD} \mathrm{simulations} \mathrm{of} \mathrm{both} \mathrm{AzoT}$ isomers were performed at $298 \mathrm{~K}$ in the presence of $1000 \mathrm{CH} 3 \mathrm{CN}$ molecules. Using Boltzmann statistics, we derived a two-dimensional Gibbs energy surface (Figure 4), as a function of the distance $\mathrm{R}$ (defined as the distance between the centre of $\mathrm{N}=\mathrm{N}$ bond of the azo group and the centre of mass of the rotor) and the dihedral angle $\theta$ (see Figure 5 for the geometrical parameters definition). The 
latter can be seen as the angle between the plane of the rotor and the plane of the stator. The $\theta=0^{\circ}$ and $\theta=180^{\circ}$ values correspond to the stator crossing the TEG macrocycle via its Azo and pyridyl groups, respectively. Three structures emerge from these calculations, named here OUT- $\left(\theta^{\sim} 180^{\circ}\right), \mathrm{MIN}-$ $\left(\theta^{\sim} 130^{\circ}\right)$ and MIN IN -stations $\left(\theta \sim 0^{\circ}\right)$ of the internal rotation and are represented along "idealized" internal rotation path is depicted schematically in Figure 6 . The light green region in Figure 4 defines a flat zone of the Gibbs energy surface which contains the equilibrium structure (MIN IN -station). Indeed, the E- and Z-AzoT molecules are characterized by dihedral angle $\theta$ values of $\mathrm{ca} .100^{\circ}$ and $\mathrm{R} \sim 10$ $\AA$ A. For both Z- and E-isomers an identical energy barrier $(2-3 \mathrm{~kJ} / \mathrm{mol})$ is found for the crossing of the pyridyl group of the stator through the rotor. Hence this process is not discriminat-ing between the $\mathrm{E}$ and $\mathrm{Z}$ - isomers and the rotational barrier is easily overcome at ambient temperature.

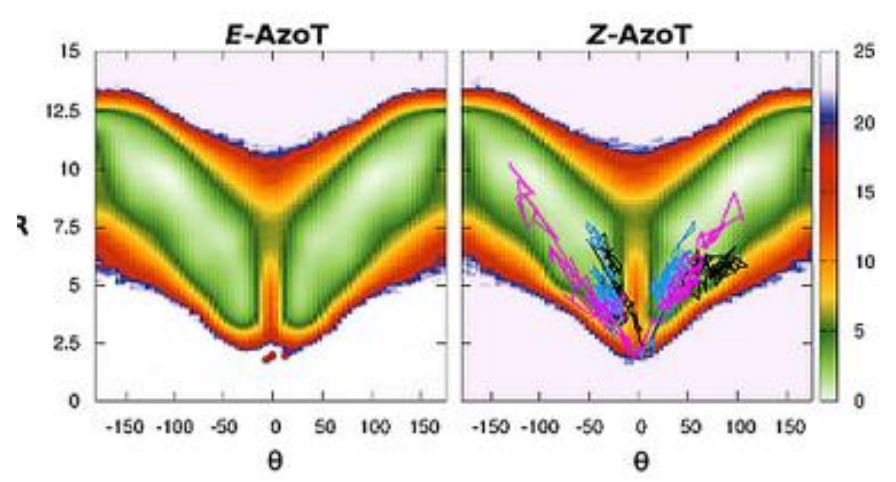

Figure 4. Gibbs energy ( $\mathrm{kJ} / \mathrm{mol}$ ) surface for EAzoT (left) and Z-AzoT (right) as a function of the dihedral angle $\theta\left({ }^{\circ}\right.$; see Figure 5 for definition) and the distance $\mathrm{R}$ (defined as the distance between the center of the $\mathrm{N}=\mathrm{N}$ bond of the azo group and the center of mass of the stator $(\AA))$ ). Pathways for the three different crossings via the MIN IN station in the case of the Z-AzoT are reported in black (crossing after $1.5 \mu \mathrm{s}$ ), blue (crossing after $13.7 \mu \mathrm{s}$ ) and magenta (crossing after $16.2 \mu \mathrm{s}$ ). The shown pathways start 50 ps before and finish 50 ps after the crossing. Snapshots along these trajectories are given in Figure 7.

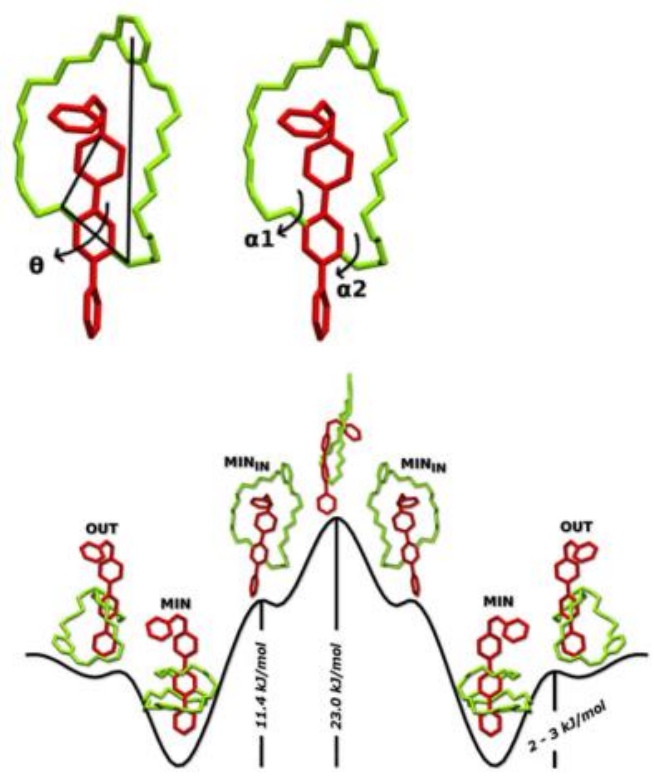

Figure 5. Definitions of the geometrical parameters $\alpha 1, \alpha 2$ and $\theta$ angles discussed in the text.

This is to be contrasted with a crossing where the Azo group enters the centre of the rotor via the MIN IN- station that is characterized by $\theta^{\sim} 0^{\circ}$ and $R \sim 2 \AA$. This region is sampled during the dynamics of the 
Z-AzoT isomer, while it is not for the E-AzoT isomer. Figure 7 shows the crossing of the stator through the centre of the rotor at three different times. From these pathways (Figure 4), the free energy barrier for Z-AzoT rotation is found to be $23.0 \mathrm{~kJ} / \mathrm{mol}$. In sharp contrast, the coordinates of the transition states of the E-AzoT isomer lie outside the regions that are sampled during the dynamics for this isomer (red dots in Figure 4), pointing out that the internal rotation is virtually forbidden in this case. DFT calculations were then performed using as starting points the geometries of the MIN IN -, OUT- and MIN-stations, which were extracted from cMD. For each isomer, full geometry DFT optimizations lead to energetically competing structures within 10-13 kJ/mol (see Table S1 in the SI). Structurally, the rotation involves dihedral angle modifications along the rotor and stator link ( $\alpha 1$ and $\alpha 2$ angles, Figure 5). Starting from a ring shape in the MIN IN -station, a conrotatory motion generates a much more compact OUT form (Figure 5). Ultimately, a significant twisting is observed, featured by a helicoidally organization of the TEG chains in the MIN station.

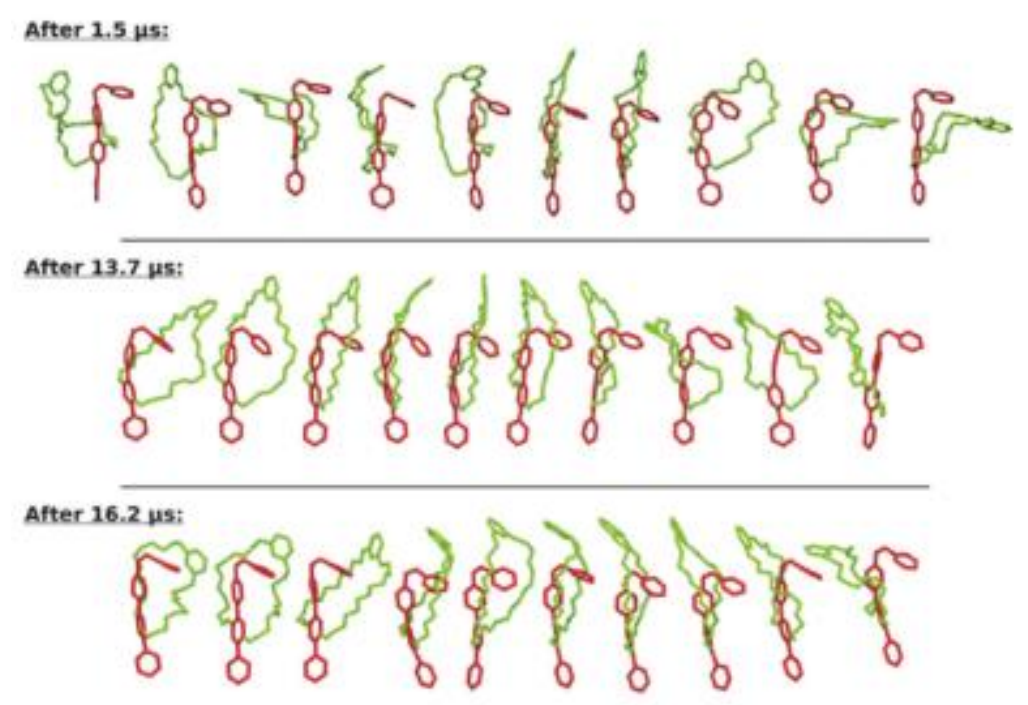

Figure 7. Z-AzoT isomer: Snapshots along the dynamics showing the crossing of the stator via the azo moiety through the centre of the rotor after $1.5 \mu \mathrm{s}$ (top), $13.7 \mu \mathrm{s}$ (middle) and $16.2 \mu \mathrm{s}$ (bottom).

The DFT calculations yield that for the E-AzoT isomer these three structures lie lower in energy than the corresponding ones for the Z-AzoT isomer. Besides, the energy difference between the OUT- and MIN-stations is about $0.07 \mathrm{eV}$ (see Table S1). Thus, the kinetics of the internal rotation must be governed by the energy of the MIN IN -station or that of a nearby lying transition structure. As displayed in Figure 6, the MIN IN -station lies $11.4 \mathrm{~kJ} / \mathrm{mol}$ above the MIN-station in Z-AzoT, suggesting that thermodynamics directly controls the Z-AzoT rotation. In contrast, the MIN IN - and MIN-stations in E-AzoT are quasi-degenerate (see Table S1). By forcing the entry of the benzyl group in the TEG loop, a barrier of $151 \mathrm{~kJ} / \mathrm{mol}$ was found from this constrained geometry. Despite its approximate character, this value supports the hypothesis of a kinetically locked internal rotation involving the two quasidegenerate structures in the E-AzoT isomer. Beyond the agreement between molecular dynamics simulations and DFT calculations, one may question the possibility for the E-isomer to overcome the barrier by tunnelling. Thus, a quantum dynamical model calculation was elaborated (see SI). From a two-level model calculation, we can exclude that tunneling takes place before $20 \mathrm{~ms}$ which is much longer than the typical duration of the classical trajectories discussed in this paper. In conclusion, the traditional picture of an internal rotation between two stable molecular structures characterized by 
local minima is revisited from NMR, UV-vis spectroscopy, molecular dynamics simulations and DFT calculations. Z/E photo-switching is evidenced using UV-vis and 2D NMR spectroscopies. A counterintuitive route that connects two local minima (MIN IN and OUT) is suggested with the existence of a third well (MIN) in the potential energy surface. From numerical inspections, the overall kinetics is governed by the passage of the Azo group inside the PEG chains loop, supporting a rotation picture. Classical molecular dynamics simulations suggest an internal rotation ( $\mu$ s timescale) of Z-AzoT governed by an estimated barrier of $23 \mathrm{~kJ} / \mathrm{mol}$. They further suggest a blockade for E-AzoT, with a DFT estimate of the barrier for the internal rotation of $151 \mathrm{~kJ} / \mathrm{mol}$.

\section{Acknowledgments}

We thank the University of Strasbourg and the Ministère de l'Enseignement Supérieur et de la Recherche for financial support and a scholarship to B.G.

\section{References}

[1] M. Schliwa, G. Woehlke, Nature 2003, 422, 759.

[2] R. D. Vale, R. A. Milligan, Science 2000, 288, 88.

[3] D. A. Fletcher, R. D. Mullins, Nature 2010, 463, 485.

[4] T. Kudernac, N. Raungsupapichat, M. Parschau, B. Maciá, N. Katsonis, S. R. Harutyunyan, K.-H. Ernst,

B. L. Feringa, Nature 2011, 479, 208.

[5] B. A. Grzybowski, W. T. S. Huck, Nat. Nanotechnol. 2016, 11, 585.

[6] W. R. Browne, B. L. Feringa, Nat. Nanotechnol. 2006, 1, 25.

[7] P. Brumer, M. Shapiro, Annu. Rev. Phys. Chem. 1992, 43, 257.

[8] M. Shapiro, P. Brumer, J. Chem. Phys. 1995, 103, 487.

[9] R. J. Gordon, S. A. Rice, Annu. Rev. Phys. Chem. 1997, 48, 601.

[10] M. Sala, F. Gatti, S. Guérin, J. Chem. Phys. 2014, 141, 164326.

[11] C. Fábri, R. Marquardt, A. G. Császár, M. Quack, J. Chem. Phys. 2019, 150, 014102.

[12] M. Sala, S. Guérin, F. Gatti, R. Marquardt, H. D. Meyer, J. Chem. Phys. 2012, 136, 194308.

[13] M. C. Jiménez, C. Dietrich-Buchecker, J. P. Sauvage, Angew. Chem. Int. Ed. 2000, 39, 3284.

[14] P. Mobian, J.-M. Kern, J. P. Sauvage, Angew. Chem. Int. Ed. 2004, 43, 2392.

[15] M. C. Jimenez-Molero, C. Dietrich-Buchecker, J. P. Sauvage, Chem. Commun. 2003, 1613.

[16] J. F. Stoddart, Angew. Chem. Int. Ed. 2017, 56, 11080.

[17] V. Balzani, M. Clemente-León, A. Credi, B. Ferrer, M. Venturi, A. H. Flood, J. F. Stoddart, Proc. Natl. Acad. Sci. USA 2006, 103, 1178.

[18] B. L. Feringa, Angew. Chem. Int. Ed. 2017, 56, 11060.

[19] V. Balzani, A. Credi, M. Venturi, (Eds.) Molecular devices and machines: concepts and perspectives for the nanoworld, Wiley-VCH Verlag GmbH, Weinheim, 2008.

[20] S. Kassem, T. van Leewen, A. S. Lubbe, M. R. Wilson, B. L. Feringa, D. A. Leigh, Chem. Soc. Rev. 2017, 46, 2592.

[21] A. Coskun, M. Banaszak, R. D. Astumian, J. F. Stoddart, B. A. Grzybowski, Chem. Soc. Rev. 2012, $41,19$.

[22] G. Ragazzon, M. Baroncini, S. Silvi, M. Venturi, A. Credi, Nat. Nanotechnol. 2015, 10, 70.

[23] M. C. Basheer, Y. Oka, M. Mathews, N. Tamaoki, Chem. Eur. J. 2010, 16, 3489.

[24] R. Thomas, N. Tamaoki, Org. Biomol. Chem. 2011, 3, 5389.

[25] A. Guenet, E. Graf, N. Kyritsakas, L. Allouche, M. W. Hosseini, Chem. Commun. 2007, 2935. 
[26] A. Guenet, E. Graf, N. Kyritsakas, M. W. Hosseini, Inorg. Chem. 2010, 49, 1872.

[27] I. N. Meshkov, V. Bulach, Y. G. Gorbunova, N. Kyrutsakas, M. S. Grigoriev, A. Y. Tsivadze, M. W. Hosseini, Inorg. Chem. 2016, 55, 10774.

[28] N. Zigon, A. Guenet, E. Graf, M. W. Hosseini, Chem. Commun. 2013, 49, 3637.

[29] N. Zigon, P. Larpent, A. Jouaiti, N. Kyritsakas, M. W. Hosseini, Chem. Commun. 2014, 50, 5040.

[30] B. Godde, A. Jouaiti, A. Fluck, N. Kyritsakas, M. Mauro, M. W. Hosseini, Dalton Trans. 2017, 46, 14897.

[31] H. M. Dhammika Bandara, S. C. Burdette, Chem. Soc. Rev. 2012, 41, 1809. [32] M.-M. Russew, S. Hecht, Adv. Mater. 2010, 22, 3348.

[33] G. Zimmerman, L.-Y. Chow, U.-J. Paik, J. Am. Chem. Soc. 1958, 80, 3528. 